\title{
How to fulfil social needs of older people: Exploring design opportunities for technological interventions
}

\author{
Tina ten Bruggencate $\mathrm{MSc}^{\mathrm{a}, \mathrm{b}, *}$ \\ Katrien G. Luijkx PhD \\ Janienke Sturm $\mathrm{PhD}^{\mathrm{b}}$
}

\begin{abstract}
${ }^{a}$ Department of Tranzo, School of Social and Behavioral Sciences, Tilburg University, Tilburg, the Netherlands; ${ }^{b}$ Chair of People and Technology, Institute for HRM and Psychology, Fontys University of Applied Science, Eindhoven, the Netherlands; *Corresponding author: t.tenbruggencate@fontys.nl
\end{abstract}

\begin{abstract}
T. ten Bruggencate, K.G. Luijkx, J. Sturm. How to fulfil social needs of older people: Exploring design opportunities for technological interventions. Gerontechnology 2019;18(3):156167; https://doi.org/10.4017/gt.2019.18.3.003.00 Social needs are important basic human needs; when not satisfied, loneliness and social isolation can occur and subsequently sickness or even premature death. For older people social needs can be more difficult to satisfy because of the loss of resources such as health and mobility. Interventions for older people to satisfy social needs are often not evaluated and when evaluated are not proven successful. Technological interventions can be successful, but the relationship between technology and social wellbeing is complex and more research in this area is needed. The aim of this research is to uncover design opportunities for technological interventions to fulfil social needs of older people. Context-mapping sessions are a way to gain more insight into the social needs of older people and to involve them in the design of interventions to fulfil social needs. Participants of the context-mapping sessions were older people and social workers working with older people. Four sessions with a total of 20 participants were held to generate ideas for interventions to satisfy social needs. The results are transcripts from the discussion parts of the context-mapping sessions and collages the participants created. The transcripts were independently analysed and inductive codes were attached to quotations in the transcripts that are relevant to the research question and subsequently thematic analysis took place. Collages made by the participants were independently analysed by the researchers and after discussion consensus was reached about important themes. The following three main themes emerged: 'connectedness', 'independence' and 'meaningfulness'. Technology was not identified as a separate theme, but was addressed in relation to the above mentioned themes. Staying active in a meaningful way, for example by engaging in volunteer work, may fulfil the three needs of being connected, independent and meaningful. In addition, interventions can also focus on the need to be and remain independent and to deal with becoming more dependent. The older people in our study have an ambivalent attitude towards technology, which needs to be taken into account when designing an intervention. We conclude this paper by making recommendations for possible technological interventions to fulfil social needs.
\end{abstract}

Keywords: context-mapping, social needs, social technology, older adults, interventions

\section{INTRODUCTION}

Social needs are important basic human needs for every individual. If social needs are not satisfied this can lead to loneliness and social isolation, which may, in turn, negatively affect a person's physical and mental health (Berkman \& Syme, 1979; Cacioppo, Hawkley, \& Berntson, 2003; Holt-Lunstad, Smith, Baker, Harris, \& Stephenson, 2015; Holt-Lunstad, Smith, \& Layton, 2010; Portero \& Oliva, 2007). A lack of close social relations or social integration is in fact seen as an important predictor of premature death (Holt-Lunstad et al., 2015; Holt-Lunstad et al., 2010). To fulfil one's social needs is therefore seen as a basic condition to improve well-being and quality of life. In our Western society where the population of older people is growing rapidly and where it is important for them to stay healthy and community-dwelling, interventions that help older people to satisfy their social needs are essential. 
There are a quite a lot of interventions for older people to improve their well-being and fulfil their social needs. The effectiveness of these interventions is evaluated only occasionally. Moreover, when the effectiveness of an intervention is evaluated, often it fails to be proven successful. One of the main reasons is that the intervention does not match the social needs of the older individual (Cattan, White, Bond, \& Learmouth, 2005; Cohen-Mansfield \& Perach, 2015; Findlay, 2003). This is due to the diversity of the population of older people and the diversity of their social needs (ten Bruggencate et al., 2018). Therefore, an intervention that will work for every older individual simply cannot exist.

Multiple studies have shown that technology can play a role in fulfilling social needs of older people, for instance the systematic literature reviews of Khosravi et al. (2016), Chen and Schulz (2016) and Cohen-Mansfield and Perach (2015). ICT (email and internet) can improve the social lives of older people, as it connects them with their friends and family. Although most technological interventions seem to have positive outcomes for social wellbeing, the review by Chen \& Schulz (2016) indicates that these effects often did not last (Chen \& Schulz, 2016). Several other studies show that there is an ambivalent relationship between digital technology and wellbeing. For instance, the study of Sum et al. (2008) revealed positive effects on social wellbeing when Internet was used to communicate with family and friends. However, using the internet for finding new network members resulted in more loneliness. In the study of Wilson (2018) positive relationships were found between frequency of use of technological devices and emotional attachment and between frequency of use and perceptions of self-worth. However, they also found a negative relationship between emotional attachment towards a device (for example a smartphone) and a sense of belonging, suggesting that older people can also be too much attached to their devices, which has a negative effect on their wellbeing. Other studies showed that there was no direct relationship between the use of social network sites and loneliness and mental health for communitydwelling older adults (Aarts, Peek, and Wouters, 2015). Thus, literature suggests that technological interventions to improve the social life of older people seem promising, but that the relationship between technology and (social) wellbeing is complex and that more research is needed.

In order to develop interventions, products and services that really meet the needs of older people, it is essential to involve older people, as well as other stakeholders such as caregivers in the design process. In fact, being emphatic and building a relationship with older people in the design pro- cess is, according to Newell, Arnott, Carmichael, and Morgan (2007), essential for the success of products for this population. A designer should really know the population he or she is designing for and actively involve them in the design process. Designers of products and services are therefore moving more closely to their target users by involving them in the creation of new products (Sanders \& Stappers, 2008). In this vision on design, also referred to as 'participatory design', human-centred design or co-design, tacit as well as latent knowledge of users' plays an important role (Sanders \& Stappers, 2008; L. Sanders \& Stappers, 2012; Spinuzzi, 2005). Context-mapping is a participatory design technique, aimed at learning about populations like older people, hearing their stories and defining design opportunities (Sanders \& Stappers, 2008; Visser, Stappers, Van der Lugt, \& Sanders, 2005). Studying the context of a population helps designers to gain empathy with users, avoid fixation on preset assumptions about the user, and create innovative concepts on how a product can be experienced (Visser et al., 2005). 'Make' and 'say' assignments let participants take small steps in constructing and expressing deeper levels of knowledge about their experiences. In our study, context-mapping sessions were aimed at learning more about the social needs and wishes of the population of older people, and how these can be translated into design opportunities. The context-mapping sessions and subsequent results presented in this article build on the results of two earlier studies. In a systematic literature review (ten Bruggencate et al., 2018) and a qualitative research (ten Bruggencate et al., 2019a) the social needs of older people and ways to satisfy these needs, including the role of social technology, were studied. Like others, we found that although the social needs of older persons are rather diverse, there are some important general elements in these social needs. Among the social needs of older people are affection, behavioural confirmation and status. The Social Production Functions - Successful Aging (SPF-SA) theory of Steverink and Lindenberg (2006) offered a strong framework for our data. Both intimate (need for affection) and more peripheral (need for behavioural confirmation and status) contacts are significant in the lives of older people. In particular, the feeling of connectedness, being useful, meaningful and independent contributes to the overall well-being of older people (ten Bruggencate et al., 2018). Social needs stay mostly congruent during a lifetime, however the resources to satisfy these needs change when ageing (Steverink \& Lindenberg, 2006). For example, because of retirement an older person can lose a sense of status and a feeling of being useful. Resources, such as one's health and mobility, diminish when a person gets older, so that social needs become harder to fulfil (Steverink \& Lindenberg, 2006; ten Bruggencate 
Table 1. Age and sex of the participants

\begin{tabular}{lcccc}
\hline $\begin{array}{l}\text { Participant } \\
\text { number }\end{array}$ & $\begin{array}{c}\text { Session 1 } \\
\text { (older people) }\end{array}$ & $\begin{array}{c}\text { Session 2 } \\
\text { (older people) }\end{array}$ & $\begin{array}{c}\text { Session 3 } \\
\text { (social workers) }\end{array}$ & $\begin{array}{c}\text { Session 4 } \\
\text { (mixed group) }\end{array}$ \\
\hline 1 & Woman, 78 & Woman, 74 & Woman, 27 & Woman, 44 \\
\hline 2 & Woman, 74 & Woman, 78 & Woman, 49 & Woman, 39 \\
\hline 3 & Woman, 82 & Man, 75 & Woman, 52 & Woman, 54 \\
\hline 4 & Man, 83 & Man, 75 & Woman, 61 & Man, 75 \\
\hline 5 & Man, 88 & Man, 76 & & Woman, 77 \\
\hline 6 & & & Woman, 87 \\
\hline
\end{tabular}

The minimum age of 75 years is based on the observation that from this age onwards resources, such as health and mobility, are more likely to diminish and social networks get more important (Antonucci, Ajrouch, \& Birditt, 2013;

et al., 2018). Older people want to contribute to the lives of others and to a community and have a meaningful life. Social technology appears to play an ambiguous role in the lives of older people. In our qualitative study (ten Bruggencate et al., 2019a) none of the 19 participants owned a smartphone. If they use some form of social technology, in most cases e-mail, they are enthusiastic and see the benefits; if they do not use social technology the older people have a more negative attitude towards it. Children and grandchildren often play a role in stimulating their parents or grandparents to use some form of (social) technology, as is also pointed out in the studies of Luijkx, Peek, and Wouters (2015) and Peek et al. (2016).

In this study, with the help of older people and social workers working with older people, we focused on collecting deeper, tacit information related to the social needs of older people and generating ideas for technological interventions to support the fulfilment of social needs.

The research question for this study is: "What are design opportunities for technological interventions aimed at fulfilling the social needs of older people according to older people themselves and social workers?"

\section{Method}

After approval from the ethical commission, approval number EC-2016.64, of the Tilburg University (ERB), qualitative data were collected using context-mapping sessions.

\section{Research design: Context-mapping}

In the context-mapping sessions, participatory and empathic design methods were applied to discover design opportunities for interventions aimed at fulfilling the social needs of older people.

\section{Participants}

The inclusion criteria for the older participants of the context-mapping sessions were:

- Age over 75 years

- Community-dwelling

- Normal verbal skills
Carstensen, Fung, \& Charles, 2003). Obviously, because of the heterogeneity of the population, any choice of age limit is to some extent arbitrary. In addition to these inclusion criteria, we tried to involve older people with a diversity in the size of their network.

We conducted four context-mapping sessions with different group compositions and with a total of 20 participants (Table 1). Two groups consisted entirely of older people. One group consisted of only social workers and one group was composed of social workers and older people. The social workers work at the LEV group, a welfare organization that offers practical and emotional help to people living in the southern region of the Netherlands.

Social workers were included in our study because we think they have good insight into the possibilities of fulfilling the social needs of older people. Moreover, social workers are important stakeholders of interventions in supporting older people in satisfying their social needs.

Two of the older (female) participants were 74 years old, and so did not meet our inclusion criteria (aged over 75 years old). We included them because their stories corresponded to that of the other older participants. Moreover, we did not find it ethical to refuse their participation.

\section{Procedure}

With the help of the LEV Group, 25 older people and social workers were selected and invited to participate in the context-mapping sessions. In April 2017 they were telephoned by the researcher and asked whether they were interested in participating in a context-mapping session. When the participants agreed to take part, they received a letter with information about the study and context-mapping session and their right to cancel at any time, without giving a reason. In this letter it was also mentioned that based on the results of this study a (technological) intervention would be developed. Because most older people do not have a lot of knowledge of the current technological possibilities, we chose not to ask the participants come up with technological interven- 
tions explicitly (Turpijn, Kneefel, \& Van der Veer, 2015). Rather, we invited them to think about and discuss their social needs and possible solutions with an open mind and a broad perspective, using creative techniques in context-mapping sessions. On the basis of the results of these sessions, we discuss the opportunities for technological interventions. This study was aimed at finding opportunities for the design of an intervention, without going into details about the specific form, technological support or organizational structure the intervention should entail.

Twenty of the 25 older people and seven social workers who were contacted agreed to participate: Three from a total of 25 people declined immediately, while two participants later cancelled because of personal circumstances. The five participants who did not participate were all older people.

All the older participants received a sensitizing workbook at least one week prior to the session. The sensitizing workbook served as a primer to be used by the older participants before the actual context-mapping session took place. With 'sensitizing', we mean that the participants are prepared for the topics in the session(s). In the course of one week, memories are triggered by self-reflection assignments. Sensitizing will give the participants insight into their experiences and enable them to talk about this more easily in a group session with other participants. With no primer there is a risk that it takes a lot of time to come up with relevant information. The workbooks were designed to be used for five days, with one assignment per day. Each daily assignment addressed one theme, based on our two previous studies (ten Bruggencate et al., 2018 and ten Bruggencate et al., 2019a). One was about their social contacts during a day (day 1): in this assignment they were asked to indicate who they had contact with during that specific day. In addition, the assignments were about close relations (day 2), volunteer work (day 3), independence (day 4) and connectedness with their environment (day 5).

Three context-mapping sessions took place at the LEV group organization, which was a convenient location for all participants. For one participant a taxi was arranged. One context-mapping session took place at the Savant group, also a convenient location for the participants of this particular session (session 4, the mixed group). The Savant group is a partner of the LEV group and a welfare organization in the south of the Netherlands. Two female researchers with a background in psychology coordinated the context-mapping sessions. The context-mapping sessions all lasted about two hours. The researchers first introduced themselves and made some practical announcements regarding the session. Each session had four to six participants (Table 1) ensuring that the group was large enough to stimulate discussion and ideas, but at the same time small enough to create a safe and comfortable atmosphere. Our context-mapping session was divided into two larger assignments.

\section{Assignment 1: Social needs (1 hour)}

In this assignment the participants were asked to individually think about what they found positive and negative in the social life of older people. The sensitizing workbook the older participants filled in the week before the session helped the participants to think about this. To make collages, participants received a toolkit with the following materials: a large piece of paper, a set of various lifestyle magazines, coloured markers and pencils and pens. Participants could use words and pictures from magazines to express these positive and negative aspects.

The assignment took about 20 minutes and afterwards the participants presented their collages to each other and to the researchers, which lasted about 15 minutes. The presentations and discussion were transcribed and analysed with the rest of the data. From this assignment negative aspects and positive aspects related to the social needs of older people were documented on a flip chart. The researchers asked every participant to name the three most important positive and negative aspects and further elaborate on why they chose these aspects. One of the researchers and the participants then made an inventory of the most important aspects from the individual collages.

\section{Assignment 2: Interventions to fulfil social needs (45 minutes)}

In this assignment groups of two or three participants selected one of the aspects of their collages, reflecting a positive or negative aspect of social life that was most urgent or important for the participants. This positive or negative aspect was written on a large sheet of paper, after which each small group of participants started generating ideas for interventions. In the case of a positive social aspect, for example, "helping others", the groups came up with ideas for how older people can realize this. This assignment took about 30 minutes. Each group then presented their solution to the other participants, which took about 15 minutes. After the presentations there was time for discussion. These presentations and discussions were also transcribed and analysed with the rest of the data.

\section{Analysis of the data}

The qualitative data collected in context-mapping sessions are rich and diverse. The discussions as well as the tangible results of the assignments contain a lot of valuable information related to 
the topic. Both assignments from the contextmapping sessions resulted in a collage. The first assignment resulted in a collage about positive and negative aspects of their social lives. In the second assignment the participants were asked to choose one of these social aspects and come up with ideas for solutions. The collages were discussed by the participants. The recorded audio of the sessions includes the discussions about the collages and other discussions that emerged for the assignments and from the group dynamics.

All audio data was transcribed verbatim. Three researchers, working in pairs, were involved in the coding process, to ensure inter-rater reliability (Boeije, 2002). Each transcript was coded independently by two of these researchers and inductive codes were attached to quotations in the transcripts that were relevant to the research question. After that, thematic analysis took place. To reach consensus, the researchers discussed their coding. Afterwards the three researchers discussed all the analysed material and consensus was reached about the three relevant themes: connectedness, independence and meaningfulness.

\section{Results}

\section{Sample descriptive}

In total, 20 people participated in the contextmapping sessions, 13 older people, of whom seven were female, and seven social workers who were all female.

\section{Themes}

The themes that emerged from our analysis are: (1) Connectedness; (2) Independence; and (3) Meaningfulness. Despite the fact that we decided not to focus explicitly on technological solutions in the context-mapping assignments, technology was addressed by most of the participants. We present the insights related to technology in relation to the three themes.

\section{Connectedness}

The participants feel connected when social ties and networks are present. This was the case for all of the participants and they did value this. Some of the participants see their social networks decline because of illness and death. The social contacts the participants have are both intimate and peripheral. Peripheral contacts help our participants in reducing or preventing social loneliness and the intimate contacts in reducing or preventing emotional loneliness. Social contacts all provide connectedness and pleasure. For the participants, their network members (both intimate and peripheral) fulfil a basic and essential need for love, company and fun. The important need to stay active is put strongly by one of the older participants. He is engaged in all kinds of volunteer work, such as getting groceries for vul- nerable people; he is also a mentor of a young student. In this way he stays connected to other people and to a community. He has a very active life himself but sees other older people passively and silently passing their time. He said:

"When you do nothing and sit passively, you fade away."

Interventions can focus on engaging in activities. This is mentioned by many of the participants as an important way to satisfy their social needs. The participants in our study engage in various activity clubs, such as a choir, bridge club or a billiards club.

The need to make a connection with other individuals is mentioned often by the participants. They feel that people are not as eager anymore to make this connection. They also see their neighbourhood changing. Younger people move into the neighbourhood and are not as open to connecting; to make contact or help one another as the participants are used to from their past. Sometimes they do not even greet when passing by, which stands in the way of social cohesion. The participants mention that a small village is in this way different from a larger city. In a village people seem to keep more of an eye on each other, they connect more. One female participant said:

"When I sit on a terrace in 'small village', I sit 5 minutes and people come over to have a little chat; when I am in 'larger city' this does not happen."

Interventions could focus on the connection to others and to a community. The participants came up with ways to connect people to each other and to a community, for example by organizing gatherings especially for older people, where they can socialize and share interests. These meetings should not be attractive only for vulnerable older people, but also for social and healthy older people. The interaction may be beneficial for both groups. Participants also think that organizing something in a neighbourhood so that people can meet and connect can enable people to help each other.

The (social) context seems to be important in the interventions and for satisfying the needs of the older individual, in this case the need for connectedness with neighbours and a neighbourhood or community. A social neighbourhood and close community can help to satisfy the social needs of older people. Some of the proposed interventions are about improving this context, for example creating a safe and social neighbourhood. Organizing a barbecue to make the neighbourhood more social and organizing a neighbourhood watch to make it more safe. In one of the sessions, a concrete solution was presented by the participants in the form of an idea for a buddy project to wel- 
come new older people in a neighbourhood. The potential benefits are that the new habitant is introduced to the people and to the activities in the neighbourhood. They even had a name for it: "Feel welcome". According to the participants, the coordination of the buddy project should be in the hands of a street coordinator, or social worker related to that neighbourhood.

The need to avoid gossip was mentioned - the older participants are anxious about gossiping. Gossiping can be (negatively) related to connectedness and contact with other people. It is possible that gossiping can be a result of a greater social cohesion and connectedness. One participant really dislikes the gossiping she encounters in her neighbourhood, and actively avoids it by avoiding social contact. She said:

"I have no need for gossiping, I stay on my own, I don't need to know what they have and what they do."

Participants came up with several ways to deal with gossiping when confronted with it. These are to be open-minded towards others and to be confident and have respect for yourself and others. But also to ignore the person who gossips or respond with an assertive reaction that will stop the gossiping. Whether these are effective ways to deal with gossiping depends on the personality and articulateness of the older person.

The need to be connected on a deeper and spiritual level was significant for the participants. Faith, religion and going to church are important for some of the participants, because it gives them support and guidance. They realize that for younger people religion does not have a prominent place in their life. The connectedness they feel with others in the same religious community and to themselves can be considered an important social need. One male participant said:

"Love, hope and faith, those are necessary, but the youth do not know that anymore."

The participants see a fast-changing society and have to deal with this in general but also socially. These changes in society are not always seen as negative. More openness to discuss certain subjects such as sexuality is seen as a positive change. One of the older participants said:

"People are more open now, for example about sex; in my days those things were covered up."

Interventions in their eyes must focus on a real interest in each other, on openness and investing in another person. These are, according to the participants, important elements of every human life. They would like to see a community that is more collectivistic and less individualistic. They see possibilities in interventions that stimulate re- spect for each other and more openness towards other people. This can be achieved by creating a social and close neighbourhood where people take the time to get to know each other and at least greet one another.

The perspective of the older participants towards (social) technology is ambivalent. Some of the participants have the feeling that technology may stand in the way of human contact and that it may make social contact more superficial. One older participant said:

"Writing a text or email, I think, is impersonal."

The sharing of all kinds of information, for example via Facebook, is seen as a violation of privacy by some of the participants. They do not understand that young people share their lives easily on, for example, Facebook. One of the participants clearly dislikes the fact that young people use their smartphone all day. At a birthday of her grandson she reprimanded a girlfriend of her grandson who was using her phone too much. She said:

"I really think it [using smartphone in a social context] is quite rude, it stands in the way of a good conversation."

This participant also mentioned that people hardly think for themselves anymore, every piece of information is found on the smartphone.

A male participant actively uses Facebook and clearly sees its possibilities and likes to share his experiences with his network. This participant has a positive attitude towards social technology. One of the participants uses Skype to contact her daughter in Australia, but she said:

"This contact (Skype) is not the same as real faceto-face contact."

The way social technology enables contact with network members can fulfill the need of connectedness. The social workers see benefits and possibilities in the use of social technology. One of the social workers said:

"I advise older people to use Facebook, so that they can easily contact their grandchildren."

\section{Independence}

The need for independence, according to our participants, means to have control over one's life. The participants of our study consider independence and (on the other side of the coin) dependence to be important themes in their lives. Independence is a social need in the sense that it is related to oneself in relation to others. Doing volunteer work contributes to a feeling of independence. One participant who does a lot of volunteer work and is engaged in all kind of activities said:

"It gives me a lot of satisfaction that I am able to help so many people." 
Interventions should focus on enabling older people to (easily) engage in volunteer work, for example through a clear and direct communication of the different options available for volunteer work. The need to be able to deal with becoming increasingly dependent is essential for the well-being of the older individual. One participant, a social worker, used her mother as an example to illustrate the importance of maintaining one's independence. Her mother became more disabled, but did not want to ask for help and therefore became increasingly isolated. She said about her mother:

"It's like a circle. By not moving anymore and not asking for help, you get isolated, you become more disabled and the chance of falling increases."

Staying independent for as long as possible is a strong desire of the participants. When staying independent becomes a problem, due to physical or cognitive disabilities, people often find it hard to ask for help, to deal with this new situation and accept it, as one of the social workers mentioned. The social workers see a threshold in older people's willingness to ask for help. Asking for help and in that way feeling dependent on other people is a big issue. One participant (social worker) said:

"That's really a big deal for them, to ask their children or neighbours for help."

Interventions in their eyes should focus on reciprocity (helping others makes it easier to ask for help for yourself) and in learning to ask for help. Reciprocity in a relationship makes older people feel less dependent, even when they receive some kind of support. They also suggested focusing on accepting that there is no shame in asking for help and that everyone needs help sometimes. For instance, an intervention could support talking with other older people who have the same experiences. To talk with others about feelings of being dependent and how to deal with this can be a relief and can give more insights into how to deal with it or maybe how to ask for help. Interventions could also take the form of support groups for older people regarding how to deal with the loss of resources.

The older participants and social workers all indicate that there are individual differences in the motivation of older individuals to engage in activities and to take control over their own lives. They state that the older person has to cross a fictional threshold when, for example, taking part in organized activities. In interventions, the social workers see a role for themselves in this. By really speaking to the older person on a deeper level and finding out about their anxieties and wishes they can better help and guide them towards (social) activities. One of the social workers said:
"You have to find out the question behind the question."

The need for a social neighbourhood with a strong social cohesion is mentioned by the participants. An example of an intervention that focuses on feeling more independent is a neighbourhood watch, so that an older person can stay community-dwelling longer, feel safe and live independently. The neighbourhood watch is an initiative by neighbours and is also carried out by them, including older persons. People keep an eye on each other and, for example, guard the neighbourhood by taking an evening walk. The participants expect that this results in a more connected neighbourhood where people know, respect and protect each other.

Technology in relation to independence was mentioned by one of the participants. This older female participant who felt quite independent in general, said that technology made her feel more dependent. She said:

"I feel that I am getting behind on things, I don't have the interest or energy to invest in learning it, but it seems necessary sometimes."

\section{Meaningfulness}

The need to do something for other people and have a meaningful life is essential to be connected to society, according to our participants. It is also the first thing the social workers mention when in the first assignment they are asked what are the important social needs for older people. One of the social workers said:

"They want to mean something to or do something for another person."

The older participants mention the need of being meaningful and useful more implicitly by pointing out the importance of helping other people, engaging in volunteer work or in activities. Reciprocal relations and activities in the sense that older people give (and take) some form of support create a sense of meaningfulness. The satisfaction and gratitude this can give is pointed out by one of the participants who helps a neighbour who has health problems. She said:

"I am very grateful that I can help her (my neighbour), she has always been a good friend."

In helping a friend or neighbour, older people feel connected, useful, independent and meaningful. Interventions can focus on people helping and caring about each other, for example a neighbourhood initiative where neighbours help each other with practical or emotional support. The social workers named an existing neighbourhood app in particular, where people can offer and ask for help. People should, according to our participants, care about other people and keep 
an eye on each other. They also argue that small things matter. No great deeds are necessary in just helping each other out. Meaningfulness can also lie in listening to each other's stories and providing the feeling that a person is heard and seen, that their lives matter. In doing something for other people the participants saw all kinds of benefits such as feeling useful, taking away lonely feelings, encouraging friendship.

The need to have a strong personality that is able to cope with every day (social) challenges is mentioned often. A couple of the interventions presented by the participants relate to the personality and active attitude of the older person. In one of the sessions this becomes clear when one of the older participants said:

"I have a lot of good social contacts, but you have to work for that, people don't just come knocking at your door."

As mentioned earlier gossip is seen by the participants as a negative aspect in their social lives. Interventions can also focus on how to avoid gossip and engage in more meaningful activities. To defend oneself from gossip demands good verbal skills and an active attitude. Interventions can hereby focus on creating a more active attitude in older people, for example in the form of workshops and courses given by behavioural experts and trainers. Obviously, to be articulate and (pro) active is a lot easier when the older person is still healthy and mobile enough to fulfil their social needs. One of the participants struggles with her health and also her daughter is very sick. Her first priority lies in caring for herself and her daughter.

\section{Discussion}

In this study we discussed how to fulfil the social needs of older people with older people themselves and with social workers who work with them. By applying a context-mapping approach to collect tacit information related to the social needs of older people, we were able to identify design opportunities for social interventions.

Overall, the participants stated that being active and involved is key to the fulfilment of social needs and to possible interventions. To engage in different activities and to be involved in the lives of others, both intimate and peripheral contacts, contributes to the well-being of older people. This is in line with the studies of Buz, Sanchez, Levenson, and Aldwin (2014) and Toepoel (2013). When an older person feels connected, independent and meaningful, important social needs are satisfied. To engage in volunteer work is important for our participants and was presented often as a possible intervention to fulfil social needs. This makes sense, because to engage in volunteer work satisfies all the three needs: connectedness, independence and meaningfulness. In doing something for someone else, the older person feels connected, independent and meaningful (Gallagher, 2012; ten Bruggencate et al., 2018; Walker \& Hiller, 2007).

The needs of being connected, independent and meaningful are interrelated, as becomes clear in the previous paragraphs and in previous studies. Connectedness is often a condition for the other two needs to be fulfilled. When people are connected, they can be meaningful, and when the connection or relationship is reciprocal the older person feels independent as is also the case for the participants of our study (ten Bruggencate et al., 2018; ten Bruggencate et al., 2019a). Interventions can focus on connecting older people to other people, to a neighbourhood and to a community.

\section{Technology and design opportunities}

Technology can be a solution for a lot of fundamental issues and can help, especially older people, to live a comfortable and happy life. However technology cannot be a solution for every problem and never should be the only solution considered. Especially in the social area, technology is not always contributing to a better (social) life as is also pointed out in the critical book of Spitzer (2012). So technology can be a powerful resource for interventions to fulfil social needs, but it should for example not replace face-toface contact. Nevertheless technology offers many opportunities for supporting older people's needs of connectedness, meaningfulness and independence. In the following sections specific recommendations are made for technological solutions for fulfilling social needs of older people, based on the insights collected in the contextmapping sessions and relevant literature. Technology can be instrumental in connecting people with their network members, with their neighbourhood and with society, especially when face-to-face contact is difficult, for instance because of physical disabilities of the older person, or when network members live far away. As the results of this study indicate older people can be connected in three ways: (1) to other people, (2) to a neighbourhood, and (3) to society.

Being connected to network members, both intimate and peripheral, is essential for the participants in our study. Various studies have shown that using social technology the contact with family and friends who live far away can be facilitated and strengthened, and that older people really benefit from using these social technologies; they are much more aware of the lives of their loved ones (Chen \& Schulz, 2016 and Sum et al, 2008). Moreover, in the study of Chen \& Schulz (2016) ICT use, primarily internet and email, was consistently found to positively affect social sup- 
port, social connectedness, and social isolation. Results indicate that technology can strengthen these existing social relations. The connectedness between different generations can also be stimulated through technology. When older people start using technology the distance that is often felt between the older and younger generation may be reduced, because they share the same interest (Peek, 2017). Furthermore, to be embedded in a close and supporting social network helps the older people to remain more independent (Ashida \& Heaney, 2008). Social technology can facilitate and strengthen the social networks of older people and in that way contribute to the feeling of independence of older people.

Our study shows that helping other people, for instance by engaging in volunteer work, may fulfill older people's need for meaningfulness as well as their needs for connectedness and independence (Gallagher, 2012; ten Bruggencate et al., 2019b). By actively participating in society they feel connected to this society. Technology can enable older people to engage in volunteer work, for example by giving relevant, clearly presented and understandable information about the volunteer work and activities available in the vicinity. Moreover, technology, for example smart algorithms, can help finding a perfect match between the interests and wishes of the older person and the offered volunteer work. Also, Facebook, Skype and WhatsApp offer possibilities for older people to share stories and experiences and to offer support and comfort.

When older people are able to use their talents and skills to help others in their neighbourhood or community they feel useful and meaningful (Walker \& Hiller, 2007; ten Bruggencate et al., 2018; Gallagher, 2012; ten Bruggencate et al., 2019a). Older people often have time to help their neighbors for example by accepting parcels, or to use their skills such as sowing, helping out in the garden or repairing small things. Special neighborhood apps may facilitate the exchange of services and goods (Capece \& Costa, 2013). The participants in our study indicated that social cohesion and a safe and pleasant neighbourhood are essential for them. Technology can play a role in strengthening social cohesion, although it is important that online and offline social networks are integrated (Wallace, Vincent, Luguzan, Townsend, and Beel, 2017).

\section{General considerations}

We found that the participants have an ambivalent attitude towards technology. Although they realize that technology may be helpful in many ways, in the eyes of the participants, technology sometimes stands in the way of real human contact. In the studies by the ten Bruggencate et al.
(2019) and Luijkx et al. (2015) it becomes clear that the negative attitude that older people may have towards social technology often changes when they start using some form of social technology, because they experience its benefits. For the successful implementation of technological interventions an important first step is therefore to change the (negative) attitude of the older person, so that they take this first step and start using the technology. Support and proper coaching by network members, for instance children and grandchildren, are essential to achieve this (Peek et al., 2016). At the same time, it is important to realize and take into account that some older people have difficulties adapting to our fastmoving technological society. Ideally, the design of an intervention is inclusive, which means that the limitations and possibilities of the population are all taken into account, so that every older individual has the possibility to benefit from the intervention (Newell \& Gregor, 2000). For an inclusive design, it is essential that the older people and other stakeholders are involved in the design process. The context-mapping method that was applied in this study employs creative techniques to give deeper insight in the tacit needs and wishes of the participants (Sanders \& Stappers, 2008).

The following considerations should be made when designing for older people: adapt to the individual user, respect their needs for privacy, use older people's frame of reference and avoid stigmatizing. First, as already mentioned, one intervention cannot match the social needs of all older individuals, due to the heterogeneity of the population (Fokkema \& Van Tilburg, 2007). Therefore, ideally, interventions should be tailormade. Technology can play a role in matching and fine-tuning interventions to the needs and capabilities of older people. The great advantage of technological devices is that they can easy be adapted to their users. Second, one of the main concerns of older people with respect to using technology is their privacy; this has also been addressed by the participants in our study (Peek et al., 2014, Yusif, Soar, \& Hafeez-Baig, 2016). Trust seems to be an important factor to consider when designing for older people, they need to be able to trust that the technology can be used safely. (Sattarov \& Nagel, 2019, McMurray et al., 2017). Furthermore, in the design of technological interventions, older people's experiences and frame of reference should be taken into consideration (Lim, 2010). In addition to the decline in abilities related to age, also the era in which older people grew up and at what age they started to first use technology determine the acceptance and effective use of new technologies, and should therefore be taken into account when designing new products and services. Finally, designers should be careful not to design and implement 
technological solutions that are stigmatizing or that emphasize the vulnerability or frailty of the older person (Yusif, Soar, \& Hafeez-Baig, 2016). The older participants in our study all are active citizens and do not want to be treated differently because of their old age.

In our Western society the focus is mainly on what we can do for older people to help them. Based on our findings, we argue that the focus should be on what older people can do for society and actively invite them to contribute. This is in line with the shift that has been taking place in the last couple of years, in countries like the Netherlands, from a welfare state to a society where participation is promoted. Older people in local communities in the Netherlands are stimulated to actively be part of the community and society (van Hees, Horstman, Jansen, \& Ruwaard, 2015). Perhaps the real solution is also a change of perception of the society towards older people and a change in what position and status they have in that society. The focus of future interventions should be more on what we can learn from the life experience and wisdom of older people. How can they contribute? This relates to the three main themes of connectedness, independence and meaningfulness.

\section{LIMITATIONS}

To engage in volunteer work is a solution to fulfilling the social needs of our participants. Most of the participants in our study were relatively active and healthy and did some form of volunteer work. It is possible that the results in that matter are biased.

Furthermore, the older participants in the context-mapping sessions were given the instruction that they could use experiences and themes from their own life, but they could also use other older people's experiences. For example, a lonely neighbour or friend. We made this choice because some older people find it difficult to think about interventions for themselves and sometimes find it difficult to accept that they need them. To have another person in mind makes it easier to talk about. The social workers were given the instruction to use examples from the older people they work with or know privately. This means that some, and in the case of the social workers all, of the information is not about the participants themselves, but about people they know or work with. The advantage is that we have more information from different perspectives. The disadvantage is that some of the information in our study is 'second-hand' and does not come directly from the older person experiencing this need or feeling.

\section{Conclusion}

Based on the findings, we argue that interventions to fulfil the social needs of older people should best focus on older people's needs to be connected, independent and meaningful. Interventions to fulfil all three needs can be found for older people by engaging in volunteer work, in helping other persons and in being open and active. We found that social cohesion and the role of a neighbourhood are important opportunities for interventions aimed at supporting the social needs of older people. We discussed the role of technology in possible interventions, considering older people's ambivalent attitude towards technology. With this study we uncovered opportunities for technological interventions to fulfil social needs based on deeper insights into these social needs.

\section{Acknowledgements}

We want to thank Marieke Otterdijk, a former student of the bachelor of applied psychology for her valuable participation in this study.

\section{References}

Aarts, S., Peek, S., \& Wouters, E. J. (2015). The relation between social network site usage and loneliness and mental health in community-dwelling older adults. 30(9), 942-949.

Antonucci, T. C., Ajrouch, K. J., \& Birditt, K. S. (2013). The convoy model: Explaining social relations from a multidisciplinary perspective. The Gerontologist, 54(1), 82-92.

Ashida, S., \& Heaney, C. A. (2008). Differential associations of social support and social connectedness with structural features of social networks and the health status of older adults. Journal of Aging and Health, 20(7), 872-893.

Berkman, L. F., \& Syme, S. L. (1979). Social networks, host resistance, and mortality: A nine-year followup study of Alameda County residents. American
Journal of Epidemiology, 109(2), 186-204.

Boeije, H. (2002). A purposeful approach to the constant comparative method in the analysis of qualitative interviews. Quality and Quantity, 36(4), 391-409.

Buz, J., Sanchez, M., Levenson, M. R., \& Aldwin, C. M. (2014). Aging and social networks in Spain: The importance of pubs and churches. The International Journal of Aging and Human Development, 78(1), 23-46.

Cacioppo, J. T., Hawkley, L. C., \& Berntson, G. G. (2003). The anatomy of loneliness. Current Directions in Psychological Science, 12(3), 71-74.

Capece, C. \& Costa, R. (2013) The new neighbourhood in the internet era: network communities serving local communities, Behaviour \& Information Technology, 32 (5), 438-448

Carstensen, L. L., Fung, H. H., \& Charles, S. T. (2003). Socioemotional selectivity theory and the regulation of emotion in the second half of life. Motivation and emotion, 27(2), 103-123.

Cattan, M., White, M., Bond, J., \& Learmouth, A. (2005). 
Preventing social isolation and loneliness among older people: A systematic review of health promotion interventions. Ageing \& Society, 25(1), 41-67. https://doi.org/10.1017/S0144686X04002594

Chen, Y.-R. R., \& Schulz, P. J. (2016). The effect of information communication technology interventions on reducing social isolation in the elderly: A systematic review. Journal of medical Internet research, 18(1).

Choi, M., Kong, S., \& Jung, D. (2012). Computer and internet interventions for loneliness and depression in older adults: A meta-analysis. Healthcare Informatics Research, 18(3), 191-198.

Cohen-Mansfield, J., \& Perach, R. (2015). Interventions for alleviating loneliness among older persons: A critical review. American Journal of Health Promotion, 29(3), e109-e125.

Findlay, R. A. (2003). Interventions to reduce social isolation amongst older people: Where is the evidence? Ageing \& Society, 23(5), 647-658.

Fokkema, T., \& Van Tilburg, T. G. (2007). Zin en onzin van eenzaamheidsinterventies bij ouderen. Tijdschrift voor Gerontologie en Geriatrie, 38(4), 161-177.

Gallagher, C. (2012). Connectedness in the lives of older people in Ireland: A study of the communal participation of older people in two geographic localities. Irish Journal of Sociology, 20(1), 84-102.

Holt-Lunstad, J., Smith, T. B., Baker, M., Harris, T., \& Stephenson, D. (2015). Loneliness and social isolation as risk factors for mortality: A meta-analytic review. Perspectives on Psychological Science, 10(2), 227-237.

Holt-Lunstad, J., Smith, T. B., \& Layton, J. B. (2010). Social relationships and mortality risk: A meta-analytic review. PLoS Medicine, 7(7), e1000316.

Khan, A. S., ur Rahman, A. \& Qazi, L. T. J. B., (2016). The relationship between internet usage, socioeconomic status, subjective health and social status. Journal of Bussiness Economic Review 8(SE), 67-82.

Khosravi, P., Rezvani, A., \& Wiewiora, A. (2016). The impact of technology on older adults' social isolation. Computers in Human Behavior, 63, 594-603.

Lim, C. S. C. (2010). Designing inclusive ICT products for older users: taking into account the technology generation effect. Journal of Engineering Design, 21(2-3), 189-206.

Luijkx, K., Peek, S., \& Wouters, E. (2015). "Grandma, You Should Do It-It's Cool" Older adults and the role of family members in their acceptance of technology. International Journal of Environmental Research and Public Health, 12(12), 15470-15485.

McMurray, J., Strudwick, G., Forchuk, C., Morse, A., Lachance, J., Baskaran, A., \& Booth, R. (2017). The importance of trust in the adoption and use of intelligent assistive technology by older adults to support aging in place: scoping review protocol. JMIR research protocols, 6(11), e218.

Newell, A., Arnott, J., Carmichael, A., \& Morgan, M. (2007). Methodologies for involving older adults in the design process. Universal Access in Human Computer Interaction. Coping with Diversity, Paper presented at 4th International Conference on Universal Access in Human-Computer Interaction, UAHCl 2007, Held as Part of $\mathrm{HCl}$ International
2007, Beijing, China, July 22-27, 2007, Proceedings, Part I 982-989.

Newell, A. F., \& Gregor, P. (2000). "User sensitive inclusive design" - in search of a new paradigm. Paper presented at the Proceedings of the 2000 Conference on Universal Usability. New York.

Peek, S. T., Luijkx, K. G., Rijnaard, M. D., Nieboer, M. E., van der Voort, C. S., Aarts, S.,. Wouters, E. J. (2016). Older adults' reasons for using technology while aging in place. Gerontology, 62(2), 226-237.

Peek, S. T. M. (2017). Understanding technology acceptance by older adults who are aging in place: $\mathrm{A}$ dynamic perspective. Tilburg University.

Portero, C. F., \& Oliva, A. (2007). Social support, psychological well-being, and health among the elderly. Educational Gerontology, 33(12), 1053-1068.

Sanders, E., \& Stappers, P. J. (2008). Co-creation and the new landscapes of design. Co-design, 4(1), 5-18.

Sanders, E., \& Stappers, P. J. (2012). Convivial design toolbox: Generative research for the front end of design: BIS Publishers: Amsterdam.

Sattarov, F., \& Nagel, S. (2019). Building trust in persuasive gerontechnology: User-centric and institutioncentric approaches. Gerontechnology, 18(1), 1-14

Spinuzzi, C. (2005). The methodology of participatory design. Technical Communication, 52(2), $163-174$.

Spitzer, M. (2012). Digital dementia: How we and our children are doing to our minds. In: Munich: Droemer.

Steverink, N., \& Lindenberg, S. (2006). Which social needs are important for subjective well-being? What happens to them with aging? Psychology and Aging, 21(2), 281.

Strauss, A., \& Corbin, J. M. (1997). Grounded theory in practice: Sage.

Sum, S., Mathews, R. M., Hughes, I., Campbell, A. J. C., \& Behavior. (2008). Internet use and loneliness in older adults. 11(2), 208-211.

ten Bruggencate, T., Luijkx, K. G., \& Sturm, J. (2018). Social needs of older people: a systematic literature review. Ageing \& Society, 38(9), 1745-1770.

ten Bruggencate, T., Luijkx, K. G., \& Sturm, J. (2019a). When your world gets smaller: how older people try to meet their social needs, including the role of social technology. Ageing \& Society, 39(8), 18261852.

ten Bruggencate, T., Luijkx, K. G., \& Sturm, J. (2019b). To Meet, to Matter, and to Have Fun: The Development, Implementation, and Evaluation of an Intervention to Fulfil the Social Needs of Older People. International journal of environmental research and public health, 16(13), 2307.

Toepoel, V. (2013). Ageing, leisure, and social connectedness: How could leisure help reduce social isolation of older people? Social Indicators Research, 113(1), 355-372.

Turpijn, L., Kneefel, S., \& Van der Veer, N. (2015). Nationale social media onderzoek 2015. Amsterdam, The Netherlands: Newcom Research Consultancy.

van Hees, S., Horstman, K., Jansen, M., \& Ruwaard, D. (2015). Betekenissen van burgerschap van ouderen in de participatiesamenleving. Tijdschrift voor gezondheidswetenschappen, 93(5), 191-196.

Visser, F. S., Stappers, P. J., Van der Lugt, R., \& Sanders, 


\section{Exploring design opportunities for technologicall interventions}

E. B. (2005). Contextmapping: Experiences from practice. CoDesign, 1(2), 119-149.

Walker, R. B., \& Hiller, J. E. (2007). Places and health: A qualitative study to explore how older women living alone perceive the social and physical dimensions of their neighbourhoods. Social Science \& Medicine, 65(6), 1154-1165.

Wallace, C., Vincent, K., Luguzan, C., Townsend, L., \& Beel, D. (2017). Information technology and social cohesion: A tale of two villages. Journal of Rural
Studies, 54, 426-434.

Wilson, C., \& Society. (2018). Is it love or loneliness? Exploring the impact of everyday digital technology use on the wellbeing of older adults. Ageing \& Society, 38(7), 1307-1331.

Yusif, S., Soar, J., \& Hafeez-Baig, A. (2016). Older people, assistive technologies, and the barriers to adoption: A systematic review. International journal of medical informatics, 94, 112-116. 